\title{
ANTONIO DI BENEDETTO (1922-1986)
}

\author{
POR \\ MALVA E. FILER \\ Brooklyn College, CUNY
}

E1 10 de octubre de 1986 murió en Buenos Aires el escritor y periodista mendocino Antonio Di Benedetto, dejando tras sí una valiosa, aunque insuficientemente estudiada, obra literaria y el recuerdo de su inalterable conducta de hombre de bien. Di Benedetto pagó el precio de su insobornable honestidad y de su aversión al oportunismo que es frecuente requisito del bienestar y el fácil prestigio. A los sesenta y tres años, el autor de Zama (1956) estaba física y psicológicamente exhausto, como consecuencia de las penurias sufridas durante catorce meses de prisión política (1976-77) y siete años de exilio (1977-1984), así como por su difícil reintegración a la Argentina, luego del restablecimiento de las instituciones democráticas, y la inseguridad económica en que vivió hasta sus últimos días. Acertado fue el juicio de Nicolás Sarquis, director cinematográfico que durante muchos años trató de filmar Zama, cuando dijo que Di Benedetto era «un hombre de una coherencia intachable. Jamás especuló con todo lo que padeció» (La Nación, lunes 13 de octubre de 1986). Este hombre retraído, pero de trato franco y afectuoso con los que lograban acercársele, fue un narrador imaginativo, original en sus temas, profundo en su visión de la vida y de gran sensibilidad y maestría en el manejo de la prosa. Se había iniciado en el periodismo aún adolescente y se desempeñó en él con talento a lo largo de una distinguida carrera. Fue subdirector del diario Los Andes, el periódico más importante de Mendoza, desde 1967 hasta 1976, cuando arrestado, sin que se dieran razones, fue encarcelado en uno de los centros clandestinos del régimen militar. En 1977, gracias a la intercesión de prestigiosos escritores argentinos y extranjeros, particularmente de Ernesto Sábato y Heinrich Böl, Di Benedetto fue puesto en libertad y salió del país. Sus años de exilio transcurrieron en Madrid, desde donde viajó a otras ca- 
pitales europeas (Roma, París, Berlín) y a los Estados Unidos, donde residió como becario de la Fundación McDowell durante el otoño del aก̃o 1981.

Paralela a la actividad periodística fue la creación literaria para el escritor mendocino. Sus primeros cuentos, recogidos en Mundo animal (1953), son contemporáneos de los de Cortázar en Bestiario. Ambos autores evocan un clima angustiante y obsesivo, pero difieren en lenguaje y en técnica narrativa. Esquemáticos, casi fragmentarios a veces, los cuentos de Mundo animal no presentan complejidad de estructura ni, en su mayor parte, un desarrollo temático, lo cual les permite mantener, en cambio, una reconcentrada y torturante intensidad. El modelo kafkiano es evidente en la temática y composición de este primer libro. Su novela El pentágono (novela en forma de cuentos), publicada en 1955 y reeditada luego con el título de Annabella (1974), es un interesante experimento narrativo. Di Benedetto se adelanta a su tiempo al escribir una obra cuyo relato no es vehículo o instrumento para describir un mundo fuera del texto. La única realidad es allí la escritura, un lenguaje que hace y deshace, compone y descompone el diseño que constituye la estructura de la novela. También experimental son los dos cuentos que componen Declinación y Angel (1958), particularmente «El abandono y la pasividad», escrito en 1954. Erróneamente se vio en este cuento una coincidencia con los principios del objetivismo que propugnaban Nathalie Sarraute y Alain Robbe Grillet, sin reparar en las obvias diferencias puntualizadas más tarde por los críticos (véase, al respecto, Jorgelina Loubet, en Nueva Critica, 1, 1970). E1 autor realizaba sus propias búsquedas, anticipándose o coincidiendo parcialmente con un movimiento de innovación literaria del que aún no tenía noticias.

La experimentación que caracteriza estas primeras obras de Di Benedetto involucra una cierta carencia de sustancia o, si se prefiere, de humanidad. El universo narrativo del autor se expande en Zama, al concebir por primera vez un personaje en el que alienta, y desíallece, el soplo de la vida. Esta obra, considerada hasta el presente su más lograda novela, introduce al lector en un drama humano hondamente vivido desde la conciencia de su protagonista, Diego de Zama. Es éste un funcionario de la Corona española anclado en el Paraguay de las postrimerías del siglo xvir, víctima de la ineficiencia y la arbitrariedad de las instituciones coloniales así como de su propia inadaptabilidad y debilidad de carácter. Anacrónicamente, el personaje tiene los rasgos del típico anti-héroe popularizado por la literatura existencialista de posguerra. Zama es, al mismo tiempo, la obra de un argentino que ha meditado su condición americana con los conceptos ideológicos de su 
propio ambiente y de su época. Di Benedetto consultó libros y recogió minuciosa información para diseñar el recinto espacial y temporal de su novela. Así como Sarmiento describió las pampas antes de haberlas visto con sus propios ojos, Di Benedetto recreó tanto el contexto geográfico como el histórico mediante la absorción, réplica y transformación de otros textos, procedentes de la crónica y la historiografía. Con gran economía y selectividad, el autor de Zama asimiló estos fragmentos del pasado, inscribiéndolos en el contexto intelectual de mediados de nuestro siglo. Al concebir su novela como un espacio de reelaboración textual, Di Benedetto se adelantó, una vez más, a las innovaciones narrativas y los conceptos críticos de los años sesenta.

De la producción posterior a Zama, recordamos especialmente «Caballo en el salitral» (1958), la novela El silenciero (1964) y «Aballay», «Onagros y hombre con renos» y «Felino de Indias», de la colección Absurdos (1978). Di Benedetto publicó un total de cinco novelas y nueve colecciones de cuentos. Recibió por sus obras numerosas menciones especiales y diversos premios, el más importante de los cuales fue el Premio «Italia-América Latina» de Literatura, otorgado en Roma (1977-78) a la novela Zama. Esta ha sido traducida al alemán, francés, italiano y polaco. Hay, también, versión alemana de El silenciero, y algunos cuentos, como «Caballo en el salitral», se encuentran publicados en otros idiomas. No existe, sin embargo, traducción inglesa de ninguna de sus obras mayores.

En años recientes, Di Benedetto publicó Cuentos del exilio (1983) y Sombras nada más... (1985), novela autobiográfica evocadora de complejas experiencias que sólo llegan al texto condensadas y transfiguradas a través del proceso onírico. Sin negar mérito a estas últimas obras, creo que ellas no están a la altura de sus mejores creaciones anteriores. Como todo autor de obra extensa, Di Benedetto muestra desniveles, en su caso tal vez agravados por las circunstancias desfavorables que marcaron la última etapa de su vida. Hay en su obra, sin embargo, un material rico e interesante, parte del cual permanece aún inexplorado. Algunos de sus cuentos son obras maestras de la narrativa breve y merecen un análisis de estilo y estructura, junto al estudio de temas y la investigación de fuentes. Confío en que lo mejor de su obra resistirá la acción destructora del tiempo y emergerá nuevamente, aligerada y prístina, para ser valorada con mayor justicia por estudiosos y críticos futuros. 
